\title{
Quantum Confinement in $\mathrm{PbI}_{2}$ Nanodisks Prepared with Cucurbit[7]uril
}

\author{
Erick M. S. dos Santos, Lourivaldo S. Pereira and Grégoire J.-F. Demets* \\ DQ-FFCLRP, Departamento de Química, Universidade de São Paulo, 14040-901 Ribeirão Preto-SP, Brazil
}

\begin{abstract}
Este trabalho apresenta uma rota alternativa para a preparação de nanodiscos de iodeto de

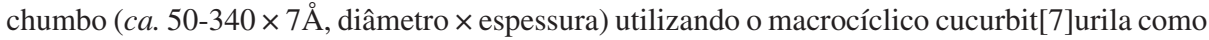
molde de síntese e agente estabilizante. Estas nanopartículas apresentam um deslocamento para o azul de gap óptico consistente com seu tamanho reduzido e confinamento quântico 1D. Suas espessuras são compatíveis com a de uma camada de iodeto de chumbo esfoliado, indicando que cucurbit[7]urila impede a formação de estruturas lamelares e limita o crescimento das nanopartículas. A estrutura, a morfologia e as propriedades destes discos foram verificadas por difratometria de raios X em pó (XRD), espectroscopia no UV-Visível, microscopia de força atômica (AFM), microscopia eletrônica de varredura com análise de fluorescência de raios X por dispersão de energia (SEM-EDS) e microscopia eletrônica de transmissão de alta resolução (HRTEM).
\end{abstract}

This work presents an alternative route for the preparation of heavy metal iodide nanoparticles, particularly lead iodide nanodisks ( $c a .50-340 \times 7 \AA$, diameter $\times$ thickness), using the macrocycle cucurbit[7]uril as a synthetic template and stabilizing agent. These nanoparticles exhibit an opticalgap blue shift consistent with their small size and 1D quantum confinement. Their thicknesses are compatible with an exfoliated single layer of lead iodide, indicating that cucurbit[7] uril, preventing the stacking and formation of tactoids, thus limiting nanoparticles growth in the $\mathrm{z}$ direction. The structure, morphology and properties of these disks were analyzed by X-ray powder diffractometry (XRD), UV-Visible spectroscopy, atomic force microscopy (AFM), scanning electron microscopy with analysis of energy dispersive X-ray fluorescence (SEM-EDS) and high resolution transmission electron microscopy (HRTEM).

Keywords: lead iodide, cucurbit[7]uril, synthetic template, nanodisks, quantum confinement

\section{Introduction}

Lead iodide is a lamellar solid consisting of layers of metal and iodide ions united by covalent bonds. Weak van der Waals interactions hold these layers together in a three dimensional sandwich-like semiconductor. This structure can be described as a hexagonal close-packed array of iodide anions with alternate layers of octahedral interstices occupied by lead(II) cations. Therefore, each layer can be described as a I-Pb-I sequence layer. ${ }^{1}$ Very interesting materials can be obtained by diminishing the $\mathrm{PbI}_{2}$ particle size to the nanoscale in order to favor the appearance of new properties resultant of quantum confinement, such as those observed in zero-dimensional solids, quantum dots and other N-dimensional, quantumconfined nanomaterials. Quantum dots encounter many applications in several technological fields such as sensor

*e-mail: greg@usp.br devices and anti-counterfeiting systems, illumination (as high efficiency white-light emitting diodes), medicine (as cellular markers), lasers, solar cells and others. ${ }^{2-5}$ Another important property of lead iodide is its ability to form intercalation compounds with many chemical species, such as hydrazine, ammonia, aniline, butylamine, pyperidine and quinoline, among others. ${ }^{1}$ The insertion of guest molecules in the interlamellar gap considerably affects the chemical and physical properties of the material.

Cucurbiturils $(\mathrm{CB}[\mathrm{n}])$ are pumpkin-shaped thoroidal molecules with two distal portals separated by $9.1 \AA$. They are produced by condensation of glycoluril and formaldehyde in acidic medium and were synthesized for the first time by Behrend et al. in 1905. ${ }^{6}$ However, their structure remained uncertain until the findings of Freeman et al., 75 years later. ${ }^{7}$ Since then, many improvements in cucurbituril synthesis, as well as in new homologue separation methods and in derivatives, have been developed by several research groups. ${ }^{8-11}$ 
The general reaction based on the condensation of glycoluril derivatives and formaldehyde leads to several homologues containing mainly 5, 6, 7 and 8 glycolurilic moieties (CB[5], $\mathrm{CB}[6], \mathrm{CB}$ [7] and $\mathrm{CB}$ [8], respectively). Among these, $\mathrm{CB}[7]$ is the only homologue with considerable solubility in water $\left(c a .30 \mathrm{mmol} \mathrm{L}^{-1}\right) .{ }^{12}$ The portals are composed by carbonyl groups and behave as Pearson's hard bases. Obviously, the portal sizes vary with the number of monomeric units, ranging from 2.4 to $6.9 \AA$ in the $\mathrm{CB}[5]-\mathrm{CB}[8]$ series. ${ }^{8,12,13}$ Cucurbituril cavities are hydrophobic and can accommodate many guest molecules in a series of inclusion compounds, just like cyclodextrins and calixarenes (see molecular structure in Figure 1). ${ }^{11}$
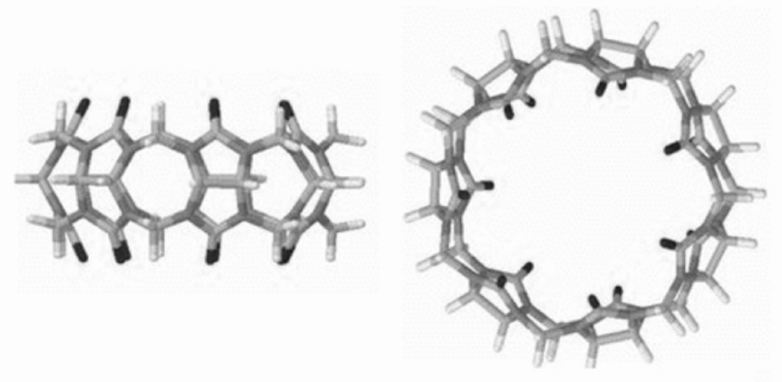

Figure 1. Representation of the chemical structure of cucurbit[7]uril.

Corma et al. ${ }^{14}$ have recently synthetized gold nanoparticles using $\mathrm{CB}$ cavities as templates, obtaining almost monodisperse particle populations, a very important aspect when one aims at absolute size control. The size control in this level is even more important during the production of quantum dots, since their physical and physicochemical properties are strongly size- and shapedependent. According to Pearson's HSAB concept, ${ }^{15} \mathrm{~Pb}^{2+}$ ions should exhibit low affinity for cucurbiturils. However, other scientists have reported high formation constants for $\mathrm{Pb}^{2+}$ and decamethylcucurbit[5]uril complexes, which is a slightly different, smaller homologue. ${ }^{16}$ There are very few works in the literature reporting on $\mathrm{CB}[\mathrm{n}]$-containing nanostructured materials, but few others encompassing gold, palladium and cadmium sulfide can be cited. ${ }^{17-19}$

In this context, we have studied the formation of colloidal lead iodide usingCB[7] acting as an external template, generating lead iodide particles with extremely reduced dimensions. We have observed the formation of randomly stacked discoid nanostructures with 1-D quantum confinement instead of small clusters.

\section{Experimental}

Cucurbit[7]uril (CB[7]) was prepared and purified as described in the literature. ${ }^{20}$ Lead iodide/CB [7] nanoparticles were prepared using $\mathrm{Pb}\left(\mathrm{NO}_{3}\right)_{2} 0.1 \mathrm{~mol} \mathrm{~L}^{-1}$ (Synth), KI (Synth) and cucurbit[7]uril $1 \times 10^{-3} \mathrm{~mol} \mathrm{~L}^{-1}$. The cucurbituril solution $(10 \mathrm{~mL})$ was kept under vigorous stirring at $27^{\circ} \mathrm{C}$ and received the addition of $100 \mu \mathrm{L}$ of the $\mathrm{Pb}\left(\mathrm{NO}_{3}\right)_{2}$ solution, followed by $200 \mu \mathrm{L}$ of the KI solution. The molar ratio between the reactants $\mathrm{CB}[7] / \mathrm{Pb}^{2+} / \mathrm{I}^{-}$ was $1: 1: 2$, respectively. The resulting mixture immediately formed a pale greenish-yellow colloid with gel-like consistence in a reproducible way, quite different from the large golden yellow crystals obtained when no CB[7] is present in the solution. This colloidal suspension was unstable and precipitated after two days. The resulting solid had the same greenish-yellow color and was washed three times with water (in order to remove the excess of $\mathrm{KNO}_{3}$ ) and dried under vacuum. For comparison purposes, reference colloidal $\mathrm{PbI}_{2}$ (2H-polytype) was synthesized exactly in the same way, except for the addition of the macrocycle.

The powder X-ray diffraction (XRD) measurements were carried out on a Siemens 5005 equipment using $\mathrm{Cu} \mathrm{K} \mathrm{K}_{\alpha}$ radiation $(\lambda=1.54 \AA)$. The diffuse reflectance spectra were measured with an Ocean optics USB 4000 spectrometer at $77 \mathrm{~K}$ (the absorption intensities were not corrected for the powder size, which is relevant for using the Kubelka-Munk function). The luminescence experiments were registered at $77 \mathrm{~K}$ using a Fluorog SPEX F2121 spectrometer equipped with a $450 \mathrm{~W}$ Xe lamp, a cooled Hamamatsu R918 photomultiplier and double excitation and emission monochromators. The atomic force microscopy images were collected on a Shimadzu SPM-9600 scanning probe microscope (contact mode). The scanning electron microscopy and energy-dispersive $\mathrm{X}$-ray spectroscopy (EDS) measurements were carried out on a Zeiss EVO 50 microscope. The samples were covered with gold by sputtering. High resolution transmission electron microscopy (HRTEM) images were obtained with a TEM-JEM 2100 ARP electron microscope. TEM sample grids were prepared by placing $1 \mu \mathrm{L}$ of the particle suspension on a carbon-coated copper grid (300 meshes) and evaporating the solvent at room temperature.

\section{Results and Discussion}

Absorption spectra of both bulk and CB-assisted $\mathrm{PbI}_{2}$ display typical semiconductor absorption profile, except for their typical absorption edge at $c a .3 \mathrm{eV}$, which is blue-shifted by $0.5 \mathrm{eV}(c a .90 \mathrm{~nm})$ for the hybrid material (Figure 2). This band to band transition is frequently very close to the exciton band, since the binding energy is very small (see Supplementary Information, SI). CB[7] does not absorb in the UV-Visible region and does not contribute to the $\mathrm{PbI}_{2}$ spectrum. It is well known that small clusters of 


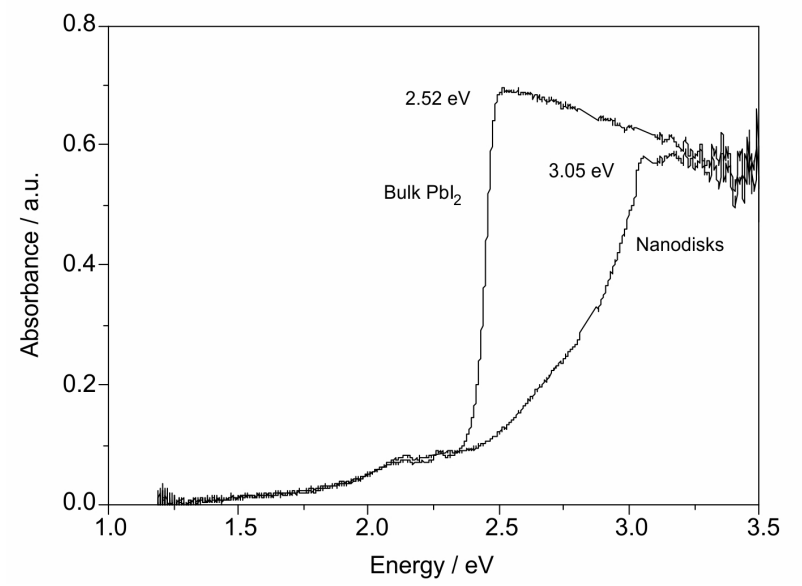

Figure 2. Absorption spectra (converted from diffuse reflectance data) of bulk $\mathrm{PbI}_{2}$ and the $\mathrm{CB}[7] / \mathrm{PbI}_{2}$ sample at $77 \mathrm{~K}$.

semi-conducting materials lead to quantum confinement of excitons in one, two or three dimensions, depending on the shape and size of the particles. ${ }^{21-29}$ In fact, the size affects the band-gap energy when the dimension becomes inferior to the bulk-exciton Bohr radius ( $c a .1 .9 \mathrm{~nm}$ for $\left.\mathrm{PbI}_{2}\right),{ }^{21,22}$ although literature reveals that $\mathrm{PbI}_{2}$ absorption edge shifts can be assigned to many other factors, from intercalation of electron-donor species between the iodide layers in few atoms clusters to ripening processes, and in low-polarity solvents. ${ }^{1,25}$ In fact, all these phenomena are interconnected and the shift is always related to quantum confinement mechanisms. Normally, low-polarity solvents tend to stabilize larger colloidal particles in detriment of the smaller ones as shown by Sandroff et al. ${ }^{24}$ but also change the dielectric constant of the medium. Small molecules can be easily intercalated into $\mathrm{PbI}_{2}$, once the layers are weakly held together, essentially by van der Waals interactions. The insertion of guest species between the layers has the same effect of that produced by negative pressure on this kind of lamellar material. In other words, the intercalation increases the interlamellar distances, lowering the electronic interaction between layers and the extent of the dispersion in the valence band. This increases considerably the energy, promoting 1D quantum confinement in the axial direction..$^{25}$

Using the effective mass approximation model, it is possible to estimate the crystallite size and thickness, as did Sandroff et al..$^{24}$ and others. ${ }^{21,22}$ Thus, in such anisotropic nanomaterial, the equation governing the band-gap shifts has the form:

$\Delta \mathrm{E}_{\mathrm{g}}=\frac{\hbar^{2}}{2 \mu_{\mathrm{xy}}}\left[\frac{2 \pi^{2}}{\mathrm{~L}_{\mathrm{xy}}^{2}}\right]+\frac{\hbar^{2}}{\mu_{\mathrm{z}}}\left[\frac{2 \pi^{2}}{\mathrm{~L}_{\mathrm{z}}^{2}}\right]$

where the effective reduced masses of the electron-hole pairs in the xy plane and in the axis perpendicular to them are represented by $\mu_{\mathrm{xy}}$ and $\mu_{z}$, respectively, and $\mathrm{L}_{\mathrm{xy}}$ and $\mathrm{L}_{z}$ are the dimensions of the crystallites. The reduced masses have been experimentally determined as $0.32\left(\mu_{\mathrm{xy}}\right)$ and $1.4\left(\mu_{z}\right)$ electron mass units, according to magneto-optic experiment data. ${ }^{24,30}$ Taking into account the absorption shift, it is reasonable to consider that almost no electronic interaction exists between the layers of $\mathrm{PbI}_{2}$ in our case, meaning that the thickness of the nanoparticles should not be larger than a single layer of $\mathrm{PbI}_{2}$. When considering a single layer of the material ( $7 \AA$ ), equation 1 becomes:

$$
\Delta \mathrm{E}_{\mathrm{g}}=\frac{235}{\mathrm{~L}_{\mathrm{xy}}^{2}}+0.55
$$

In our case, the shift observed is $3.10-2.56 \mathrm{eV}=0.54 \mathrm{eV}$. According to equation 2, this value corresponds to the shift caused by the exfoliation of the structure, independently of the size of layers, which are too large to produce any spectral shift (the first term of such equation tends to 0 when $L_{z}=7 \AA$ ). Thus, the spectral shift observed for the $\mathrm{CB}[7] / \mathrm{PbI}_{2}$ sample is consistent with nanoflakes constituting of $\mathrm{PbI}_{2}$ monolayers stabilized by the macrocycle. No fluorescence at all could be measured for the hybrid solid $\mathrm{CB}[7] / \mathrm{PbI}_{2}$, indicating that the electron-hole pairs in these crystals are captured by surface traps and quenched by nonradiatively recombination processes. This is a quite common phenomenon in quantum-confined nanocrystals. ${ }^{26,31,32}$

The X-ray diffraction patterns of the pure $\mathrm{PbI}_{2}$ and $\mathrm{CB}[7] / \mathrm{PbI}_{2}$ sample are compared in Figure 3. Pure $\mathrm{PbI}_{2}$ exhibits very sharp and intense peaks characteristic of crystalline materials, while $\mathrm{CB}[7] / \mathrm{PbI}_{2}$ reveals an amorphous structure, with a total loss of structural

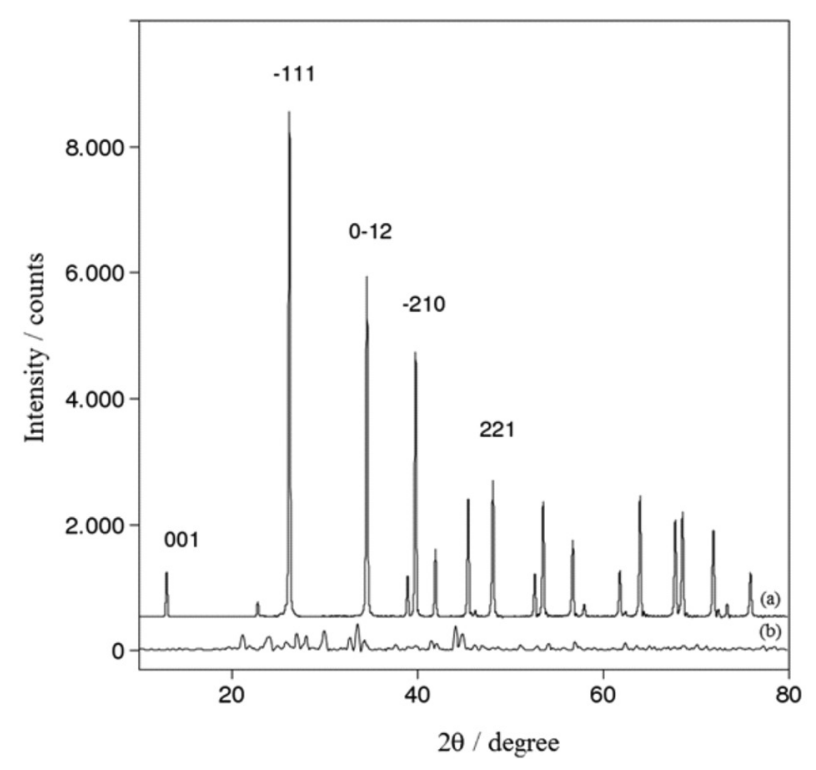

Figure 3. $\mathrm{XRD}$ patterns of pure $\mathrm{PbI}_{2}$ (a) and of the $\mathrm{CB}[7] / \mathrm{PbI}_{2}$ sample (b). 
coherence. In fact, the absence of the 001 peak for the hybrid structure suggests the absence of a regular ordering of the $\mathrm{PbI}_{2}$ layers and it is expected for more or less randomly-oriented isolated nanoflakes consisting of iodide monolayers. According to this, it is possible to conclude that no continuous turbostratic structure can be present, because the size of the clusters is too small for this. According to Sandroff et al. ${ }^{24}$ the interlayer distance of lead iodide can vary depending on the synthetic procedure, but it is never inferior to $12 \AA$, while the thickness of a single layer is $7 \AA$. The height of $\mathrm{CB}[7]$ molecule is $9.1 \AA$ and should provoke an expansion of the basal distance of this magnitude if it is intercalated between the layers, acting as a pillar in the structure. An important factor that must be considered is sterical hindrance: cucurbit[7]uril is a very large molecule (ca. $9 \AA$ ) and it is geometrically impossible to keep a 1:1 $\mathrm{Pb}^{2+} / \mathrm{CB}$ [7] ratio inside a lamellar structure. Therefore, part of the macrocycle molecules would be pushed out from the structure or the iodide would be forced to adopt a crystalline configuration different from the lamellar one. Furthermore, $\mathrm{K}^{+}$ions are present in large amounts in the reaction medium and it is certain that they bind the macrocycle portals, forming large cationic species in solution. These positively charged species may interact with iodine ions by electrostatic interactions, but it was verified that electron-donor species are better guests for intercalation in lead iodide. In other words, nothing favors the formation of lamellar structures in this case. ${ }^{33-38} \mathrm{~A}$ few and very weak signals may be observed in the diffraction pattern of the hybrid material. Even using the best acquisition methods, it is impossible to state, with our equipment, that these signals are peaks and not noise, since they are not reproducible. Furthermore, the signal does not correspond to any known $\mathrm{PbI}_{2}$ polytype.

Medium resolution SEM micrographs $(\times 2,000$ magnification) reveal overlaid sheets of $\mathrm{PbI}_{2}$, just as in the case of re-crystallized matrices. ${ }^{33}$ A SEM image obtained with high magnification $(\times 200,000)$ shows that these sheets are made of small disks measuring around $50 \mathrm{~nm}$ (Figure 4). EDS spectra display strong lead, iodine, carbon, oxygen and potassium signals arising from the sample (data not shown). The detected potassium is probably reminiscent from the $\mathrm{KI}$ starting material. This fact is easily understood once, as already mentioned, $\mathrm{K}^{+}$ions form very stable coordination compounds with cucurbiturils. ${ }^{39}$

The presence of the nanodisks was confirmed by AFM imaging, making clear that the sheets are composed by aggregates of regular disk-like particles. The average size was estimated to be around $34 \mathrm{~nm}$ (Figure 5). HRTEM images show these disks as single sheets of lead iodide that are totally exfoliated, forming a "house of cards" structure (Figure 6). This kind of structure is frequently observed in

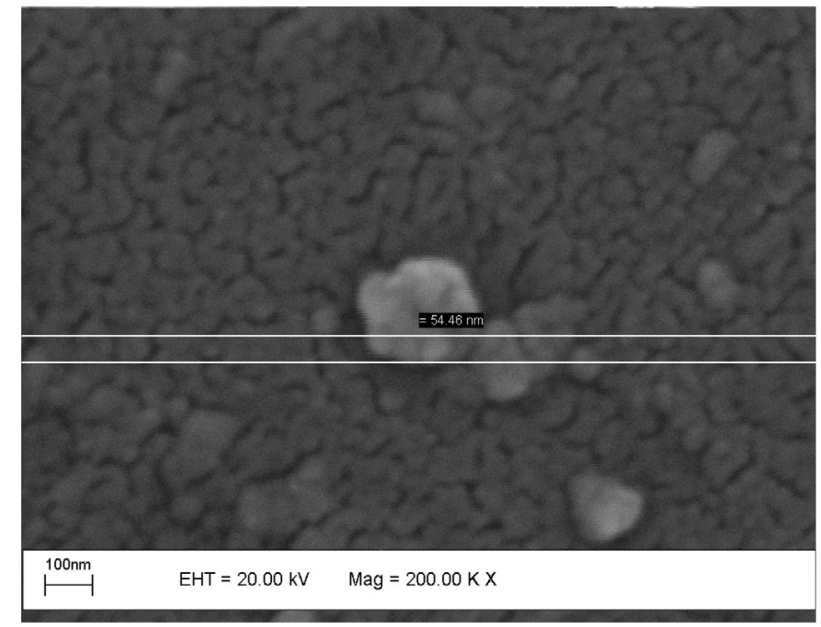

Figure 4. SEM image of the $\mathrm{CB}[7] / \mathrm{PbI}_{2}$ sample with aggregates under $\times 200,000$ magnification. The grain size estimated in $54 \mathrm{~nm}$.

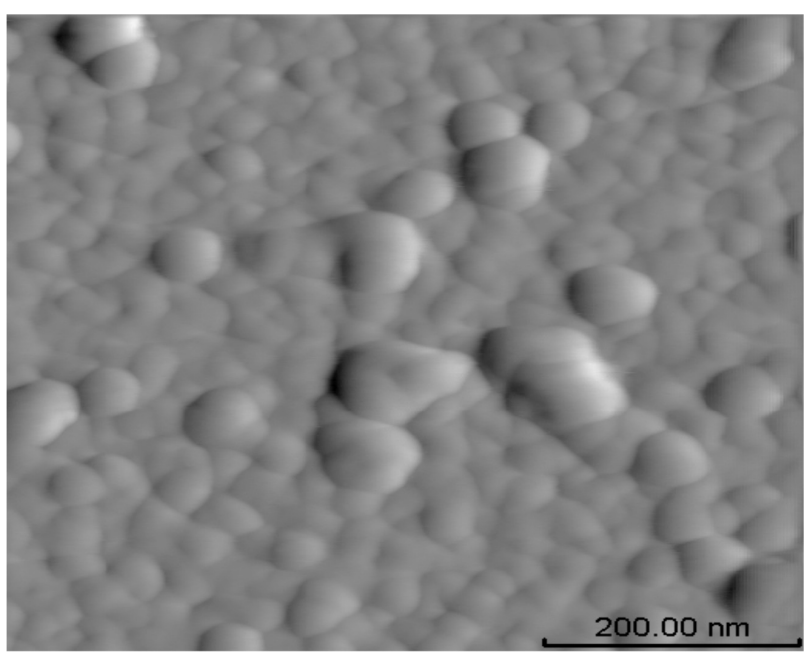

Figure 5. AFM micrograph of the $\mathrm{CB}[7] / \mathrm{PbI}_{2}$ sample with $\mathrm{CB}[7] / \mathrm{PbI}_{2}$ nanoparticle aggregates.

exfoliated clay gels, for instance Laponite ${ }^{\circledR}$. In this synthetic smectite, the gel is formed by weak interactions between $1 \times 25$ nm disks. ${ }^{40}$

\section{Conclusions}

$\mathrm{CB}[7]$ does not act as a hollow shell template for lead iodide formation as it does in the case of metal nanoparticles. The present work indicates that the macrocycle forms a random structure composed of small $\mathrm{PbI}_{2}$ disks separated by $\mathrm{CB}$ [7] and $\mathrm{K}^{+}$ions. The hybrid material presents reduced interlayer coupling terms, which affect its absorption spectrum when compared to pure $2 \mathrm{H}-\mathrm{PbI}_{2}$. The mechanism involved in the formation of this nanomaterial is complex, since it starts from an unstable colloid, which then sediments. A possible mechanism could be proposed with three major steps: the first is the formation of $\mathrm{K}_{2} \mathrm{CB}[7]^{2+}$ 


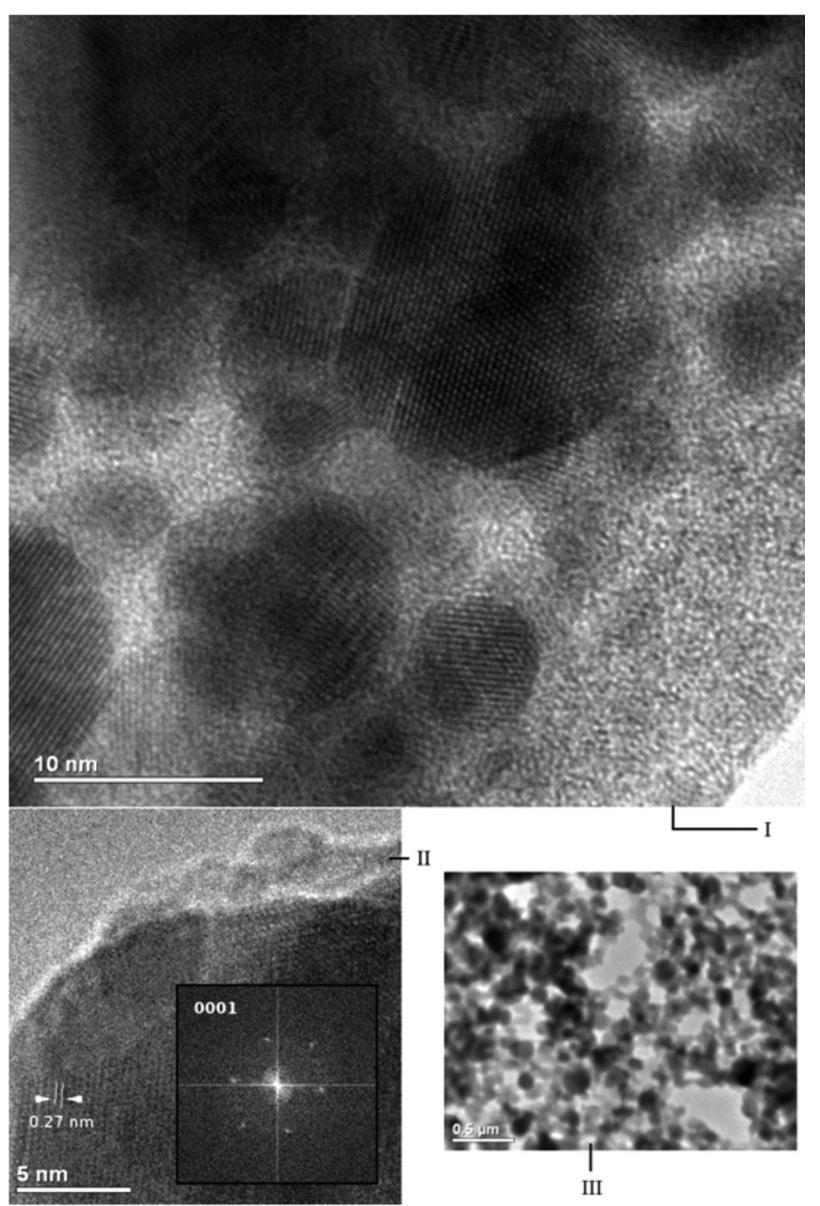

Figure 6. HRTEM micrographs of (I) the $\mathrm{CB}[7] / \mathrm{PbI}_{2}$ sample; (II) a single $\mathrm{PbI}_{2}$ nanodisk (diameter $\mathrm{ca} .30 \mathrm{~nm}$ ), inset: electron diffraction pattern; and (III) $\mathrm{CB}[7] / \mathrm{PbI}_{2}$ sample under higher magnification, with random nanodisks in a "house of cards" arrangement.

cations which interact with iodine ions in solution. Then, lead ions bind the halogens forming nucleation centers for lead iodide single layers. As the single layers grow, $\mathrm{CB}$ [7] becomes too bulky and is gradually pushed to their borders, limiting nanoparticle growth. Another possibility is the formation of adducts with water molecules and $\mathrm{Pb}^{2+}$ ions instead of potassium complexes during the nucleation process, because this kind of structure has already been observed in many cases and with several metal ions. The nanodisk formation mechanism is still being investigated with other metal halides and will be the subject of another paper.

\section{Supplementary Information}

Additional information about the exciton band of lead iodide, including the absorption spectra of solid $\mathrm{PbI}_{2}$ and $\mathrm{PbI}_{2}$ nanodisks (Figure $\mathrm{S} 1$ ), is available free of charge at http://jbcs.sbq.org.br as PDF file.

\section{Acknowledgements}

We sincerely thank Dr. Ivana Aparecida Borin and Dr. Rodrigo Ferreira Silva for microscopy images, as well as Prof. Koiti Araki, Prof. Antonio Osvaldo Serra and Prof. Paulo César da Souza Filho for fluorescence measurements. This work was sponsored by the Conselho Nacional de Desenvolvimento Científico e Tecnológico (CNPq), Coordenação de Aperfeiçoamento de Pessoal de Nível Superior (CAPES) and Fundação de Amparo à Pesquisa do Estado de São Paulo (FAPESP). HRTEM images were obtained at Laboratório Nacional de Luz Síncrotron (LNLS, Campinas-SP, Brazil)(TEM-MSC-9054).

\section{References}

1. Coleman, C. C.; Goldwhite, H.; Tikkanen, W.; Chem. Mater. 1998, 10, 2794.

2. Michalet, X.; Pinaud, F. F.; Bentolila, L. A.; Tsay, J. M.; Doose, S.; Li, J. J.; Sundaresan, G.; Wu, A. M.; Gambhir, S. S.; Weiss, S.; Science 2005, 307, 538.

3 Xu, T.; Nikiforov, A. Y.; France, R.; Thomidis, C.; Williams, A.; Moustakas, T. D.; Phys. Status Solidi A 2007, 204, 2098.

4. Tang, J.; Sargent, E. H.; Adv. Mater. 2010, $20,1$.

5. Hendrick, E.; Frey, M.; Herz, E.; Wiesner, U.; J. Eng. Fibers Fabr. 2010, 5, 21.

6. Behrend, R.; Meyer, E.; Rusche, F.; Liebigs J.; Ann. Chem. 1905, 339, 1.

7. Freeman, W. A.; Mock, W. L.; Shih, N.-Y.; J. Am. Chem. Soc. 1981, 103, 7367.

8. Day, A.; Arnold, A. P.; Blanch, R. J.; Snushall, B.; J. Org. Chem. 2001, 66, 8094.

9. Day, A. I.; Blanch, R. J.; Arnold, A. P.; Lorenzo, S.; Lewis, G. R.; Dance, I.; Angew. Chem., Int. Ed. 2001, 41, 275

10. Kim, J.; Jung, I.-S.; Kim, S.-Y.; Lee, E.; Kang, J.-K.; Sakamoto, S.; Yamaguchi, K.; Kim, K.; J. Am. Chem. Soc. 2000, 122, 540.

11. Liu, S.; Ruspic, C.; Mukhopadhyay, P.; Chakrabarti, S.; Zavalij, P. Y.; Isaacs, L.; J. Am. Chem. Soc. 2005, 127, 15959.

12. Lagona, J.; Mukhopadhyay, P.; Chakrabarti, S.; Isaacs, L.; Angew. Chem., Int. Ed. 2005, 44, 4844.

13. Demets, G. J.-F.; Quim. Nova 2007, 30, 1313.

14. Corma, A.; Garca, H.; Montes-Navajas, P.; Primo, A.; Calvino, J. J.; Trasobares, S.; Chem. Eur. J. 2007, 13, 6359.

15. Pearson, G. R.; Inorg. Chem. 1988, 27, 734.

16. Zhang, X. X.; Krakowiak, K. E.; Xue, G.; Bradshaw, J. S.; Izatt, R. M.; Ind. Eng. Chem. Res. 2000, 39, 3516.

17. Lee, T.-C.; Scherman, O. A.; Chem. Commun. 2010, 46, 2438. 18. Li, M.; Zaman, M. B.; Bardelang, D.; Wu, X.; Wang, D.; Margeson, J. C.; Leek, D. M.; Ripmeester, J. A.; Ratclife, C. I.; Lin, Q.; Yange, B.; Yu, K.; Chem. Commun. 2009, 44, 6807. 
19. Cao, M.; Lin, J.; Yang, H.; Cao, R.; Chem. Commun. 2010, 46 , 5088.

20. Day, A. I.; Arnold, A. P.; Blanch, R. J.; Snushall, B.; J. Org. Chem. 2001, 66, 8094.

21. Mallik, K.; Dhami, T. S.; Phys. Rev. B: Condens. Matter Mater. Phys. 1998, 58, 13055.

22. Finlayson, C. E.; Sazio, P. J. A.; J. Phys. D: Appl. Phys. 2006, 39, 1477.

23. Nozue, Y.; Tang, Z. K.; Goto, T.; Solid State Commun. 1990, $73,531$.

24. Sandroff, C. J.; Kelty, S. P.; Hwang, D. M.; J. Chem. Phys. 1986, 85, 5337.

25. Ghorayeb, A. M.; Coleman, C. C.; Yoffe, A. D.; J. Phys. C: Solid State Phys. 1984, 17, L715.

26. Artemyev, M. V.; Rakovich, Y. P.; Yablonski, G. P.; J. Cryst. Growth 1997, 171, 447.

27. Barnakov, Y. U.; Ito, S.; Dmitruk, I.; Tsunekawa, S.; Kasuya, A.; Scr. Mater. 2001, 45, 273.

28. Micic, O. I.; Zongguan, L.; Mills, G.; Sullivan, J. C.; Meisel, D.; J. Phys. Chem. 1987, 91, 6221.

29. Tubbs, M. R.; Forty, A. J.; J. Phys. Chem. Solids 1965, 26, 711.

30. Sandroff, C. J.; Hwang, D. M.; Chung, W. M.; Phys. Rev. B: Condens. Matter Mater. Phys. 1986, 33, 5953.

31. Dag, I.; Lifshitz, E.; J. Phys. Chem. 1996, 100, 8962.
32. Sengupta, A.; Jiang, B.; Mandal, K. C.; Zhang, J. Z.; J. Phys. Chem. B 1999, 103, 3128.

33. Schaefer, R. W.; Ardelean, M.; Powder Diffr. 2001, 16, 16.

34. Agrawal, V. K.; Chadha, G. K.; Trigunayat, G. C.; Acta Cryst. 1970, A26, 140.

35. Chand, M.; Trigunayat, G. C.; Acta Cryst. 1975, B31, 1222.

36. Flahaut, E.; Sloan, J.; Friedrichs, S.; Kirkland, A. I.; Coleman, K. S.; Williams, V. C.; Hanson, N; Hutchison, J. L.; Green, M. L. H.; Chem. Mater. 2006, 18, 2059.

37. Kasi, G. K.; Dollahon, N. R.; Ahmadi, T. S.; J. Phys. D: Appl. Phys. 2007, D40, 1778.

38. Koutselas, I.; Dimos, K.; Bourlinos, A.; Gournis, D.; Avgeropoulos, A.; Agathopoulos, S.; Karakassides, M. A.; J. Optoelectron. Adv. Mater. 2008, 10, 311.

39. Buschmann, H. J.; Cleve, E.; Schollmeyer, E.; Inorg. Chim. Acta 1992, 193, 93.

40. Kroon, M.; Vos, W. L.; Wegdam, G. H.; Int. J. Thermophys. 1998, 19, 887 .

Submitted: August 21, 2010

Published online: May 24, 2011

FAPESP has sponsored the publication of this article. 


\title{
Quantum Confinement in $\mathrm{PbI}_{2}$ Nanodisks Prepared with Cucurbit[7]uril
}

\author{
Erick M. S. dos Santos, Lourivaldo S. Pereira and Grégoire J.-F. Demets* \\ DQ-FFCLRP, Departamento de Química, Universidade de São Paulo, 14040-901 Ribeirão Preto-SP, Brazil
}

\section{On lead iodide exciton band}

The exciton band of lead iodide does not appear always as a sharp and intense peak. Its shape and intensity may vary with crystal form, polytype, temperature, light polarization, synthetic procedure, crystallite size and especially with the purity of the material. ${ }^{1}$ Many authors have reported similar spectra, for which the absorption edge is associated with the excitonic level, separated from gap transitions by few $\mathrm{meV}$, since the binding energy is very small. The presence of electron donors in solution also affects exciton absorption bands, as demonstrated in other papers..$^{2-5}$ It is well described in the literature that the first excitonic band may undergo blue shifts when extremely small particles are obtained. ${ }^{1,6-8}$ In the present work, a set of optical fibers and a light source essentially designed for Vis-NIR region were used in the first attempts to obtain absorption spectra. This could be the reason for the lack of spectral resolution. Furthermore, the Kubelka-Munk function could not be used since no information about the powder size of the samples after drying the colloid was known. The UV-Vis absorption measurements were repeated at room temperature (Figure S1), using another set of optical fibers designed for working in the UV region. This time the bands clearly appear. Using the Tauc equation, the $\mathrm{E}_{\mathrm{g}}$ value was calculated, being 2.34 and $2.80 \mathrm{eV}(\mathrm{diff}=0.46 \mathrm{eV})$ for bulk $\mathrm{PbI}_{2}$ and the nanodisks, respectively.

For pure lead iodide, the exciton band is located at the absorption edge (499 nm), which is coherent with the literature (490-500 nm). For the nanodisks, it is blue-shifted to $387 \mathrm{~nm}$ and a small shoulder is observable at $499 \mathrm{~nm}$, which could be assigned to larger aggregates or to heteronuclear excitons. ${ }^{3}$ As mentioned before, these new values were obtained at room temperature, but the onset absorption energies do not vary considerably from our previous measurements at $77 \mathrm{~K}$ (see Figure 2 in the main text), and would not affect the presented conclusions from the effective mass model. Probably, the problem is related to our experimental apparatus.

*e-mail: greg@usp.br

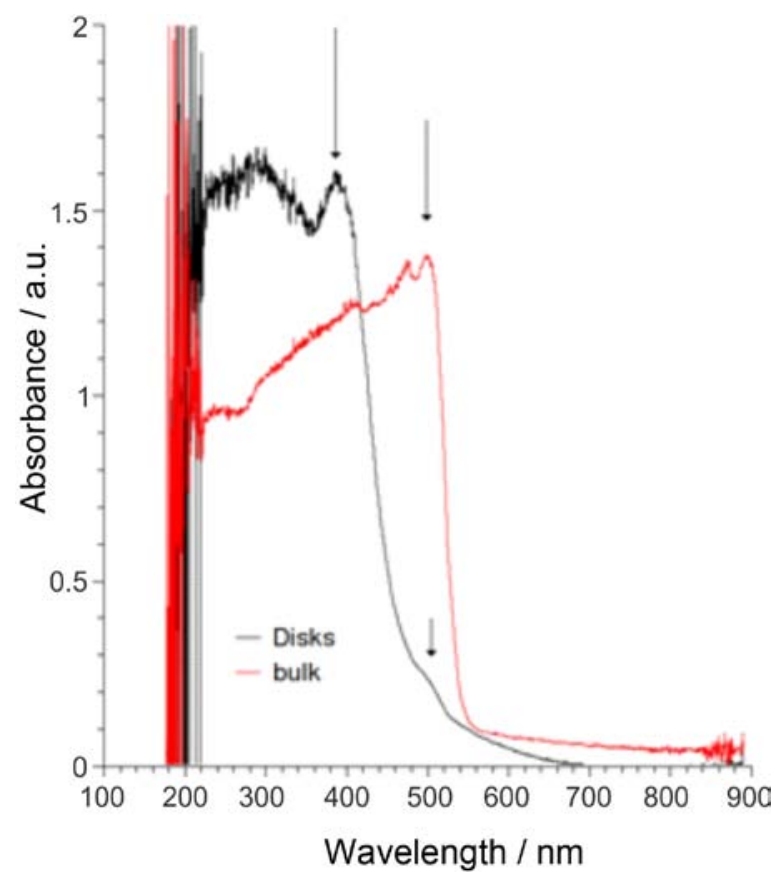

Figure S1. Absorption spectra of solid $\mathrm{PbI}_{2}$ and $\mathrm{PbI}_{2}$ nanodisks at room temperature.

\section{References}

1. Tubbs, M. R.; Forty, A. J.; J. Phys. Chem. Sol. 1965, 26, 711. (29 in the Article text).

2. Sengupta, A.; Jiang, B.; Mandal, K. C.; Zhang, J. Z.; J. Phys. Chem. B 1999, 103, 3128. (32 in the Article text).

3. Bhavsar, D. S.; Saraf, K. B.; J. Mater. Sci.: Mater Electron. 2003, 14, 195.

4. Koutselas, I.; Dimos, K.; Bourlinos, A.; Gournis, D.; Avgeropoulos, A.; Agathopoulos, S.; Karakassides, M. A.; J. Optoelectron. Adv. Mat. 2008, 10, 311.

5. Nozue, Y.; Tang, Z. K.; Goto, T.; Solid State Commun. 1990, 73, 531. (23 in the Article text).

6. Kasi, G. K.; Dollahon, N. R.; Ahmadi, T. S.; J. Phys. D: Appl. Phys. 2007, 40, 1778. (37 in the Article text).

7. Artemyev, M. V.; Rakovich, Y. P.; Yablonski, G. P.; J. Cryst. Growth 1997, 171, 447. (26 in the Article text).

8. Micic, O. I.; Li, Z.; Mills, G.; Sullivan, J. C.; Meisel, D.; J. Phys. Chem. 1987, 91, 6221. 